\title{
Arterial coronary artery bypass grafting is safe and effective in elderly patients
}

\author{
Benjamin Medalion, MD, ${ }^{\mathrm{b}, \mathrm{c}}$ Rephael Mohr, MD, ${ }^{\mathrm{a}, \mathrm{c}}$ Ynai Ben-Gal, MD, ${ }^{\mathrm{a}, \mathrm{c}}$ Nachum Nesher, MD, ${ }^{\mathrm{a}, \mathrm{c}}$ \\ Amir Kramer, MD, ${ }^{a, c}$ Shimrit Eliyahu, MD ${ }^{c}$ and Dmitry Pevni, MD $^{\mathrm{a}, \mathrm{c}}$
}

\begin{abstract}
Objectives: Bilateral internal thoracic artery grafting in elderly patients is controversial. We compared the outcome of bilateral internal thoracic artery grafting with that of single internal thoracic artery and saphenous vein and radial artery conduits in these patients.

Methods: Patients aged 70 years or more who underwent bilateral internal thoracic artery grafting between 1996 and $2008(n=1045)$ were compared with patients who underwent coronary artery bypass grafting with a single internal thoracic artery + saphenous vein graft $(n=582)$ or a single internal thoracic artery + radial artery $(\mathrm{n}=249)$.

Results: Prevalence of female gender, diabetes, emergency operation, and chronic obstructive pulmonary disease was lower in the bilateral internal thoracic artery grafting group compared with the internal thoracic artery + radial artery and internal thoracic artery + saphenous vein graft groups, whereas congestive heart failure and recent myocardial infarction were more prevalent in the bilateral internal thoracic artery grafting group. Operative mortality and sternal wound infections were not significantly different between groups. The mean follow-up was $8.17 \pm 4.45$ years. Ten-year survival (Kaplan-Meier) in the internal thoracic artery + saphenous vein graft group was significantly lower than in the bilateral internal thoracic artery grafting and internal thoracic artery + radial artery groups $(P<.001)$. Assignment to the saphenous vein graft group was also associated with decreased adjusted survival $(P<.001)$ compared with the bilateral internal thoracic artery and internal thoracic artery + radial artery groups.
\end{abstract}

Conclusions: This study supports the use of arterial grafts in elderly patients undergoing coronary artery bypass grafting. (J Thorac Cardiovasc Surg 2015;150:607-12)

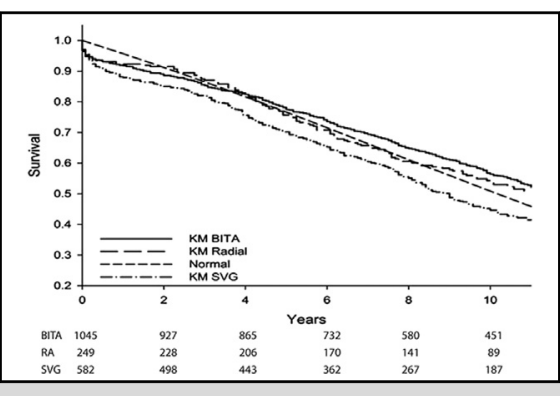

Survival of patients undergoing arterial grafting compared with a single ITA + SVG.

\section{Central Message}

Patients aged 70 years or more who underwen BITA or SITA + RA grafting have better longterm survival than patients who underwent ITA + SVG

\section{Perspective}

The findings of our study support the use of BITA and RA in patients aged more than 70 years. They show similar rates of sternal wound complications and improved long-term survival of patients who underwent $\mathrm{CABG}$ with arterial grafts compared with a single ITA and SVG.
Bilateral internal thoracic artery (BITA) grafting is associated with improved survival compared with a single internal thoracic artery (ITA) and saphenous vein graft (SVG). ${ }^{1}$ In addition to improved survival, patients who underwent BITA reportedly had better event-free survival and reduced occurrence of reinterventions. ${ }^{1}$ Despite the improved long-

\footnotetext{
From the ${ }^{\mathrm{a}}$ Department of Cardiothoracic Surgery, Tel Aviv Sourasky Medical Center, Tel Aviv, Israel; ' Department of Cardiothoracic Surgery, Rabin Medical Center, Petach Tiqva, Israel; and ${ }^{\mathrm{c} S}$ Sackler School of Medicine, Tel Aviv University, Tel Aviv, Israel.

Received for publication Dec 15, 2014; revisions received June 9, 2015; accepted for publication June 13, 2015; available ahead of print July 16, 2015.

Address for reprints: Rephael Mohr, MD, Department of Cardiothoracic Surgery, Tel Aviv Sourasky Medical Center, 6 Weizman St, Tel Aviv 64239, Israel (E-mail: pevnid@gmail.com).

$0022-5223 / \$ 36.00$

Copyright (C) 2015 by The American Association for Thoracic Surgery

http://dx.doi.org/10.1016/j.jtcvs.2015.06.032
}

term outcome, surgeons are reluctant to use BITA grafting in the elderly because of the excellent survival benefit obtained with single ITA $^{2,3}$ and the increased risk of sternal dehiscence and sternal infection ${ }^{4-6}$ caused by the more extensive devascularization associated with harvesting 2 ITAs. ${ }^{7,8}$

Extensive arterial grafting with BITAs has been used preferentially in a selected group of young male, nonobese, nondiabetic patients in several studies. ${ }^{9-11}$ Patients were preselected for BITA grafting according to their life expectancy, and only a few patients aged more than 70 years were offered the option of BITA grafting. Unlike in those trials, we did not preselect patients for BITA grafting according to their life expectancy and performed complete arterial grafting with BITAs as the preferred method of myocardial revascularization for all age groups throughout the study period. ${ }^{12}$ We used BITA grafting in 


$$
\begin{array}{ll}
\text { Abbreviations and Acronyms } \\
\text { BITA } & =\text { bilateral internal thoracic artery } \\
\text { CABG } & =\text { coronary artery bypass grafting } \\
\text { CI } & =\text { confidence interval } \\
\text { COPD } & =\text { chronic obstructive pulmonary } \\
& \text { disease } \\
\text { euroSCORE }= & \text { European System for Cardiac } \\
& \text { Operative Risk Evaluation } \\
\text { HR } & =\text { hazard ratio } \\
\text { ITA } & =\text { internal thoracic artery } \\
\text { OBCAB } & =\text { off-pump coronary artery bypass } \\
\text { RA } & =\text { radial artery } \\
\text { RCA } & =\text { right coronary artery } \\
\text { RITA } & =\text { right internal thoracic artery } \\
\text { SVG } & =\text { saphenous vein graft }
\end{array}
$$

$61 \%$ of the patients who were referred for coronary artery bypass grafting (CABG), and $41 \%$ of the entire cohort was aged 70 years or more. The goal of our current study was to compare the outcome of BITA grafting with that of single ITA and other conduits, such as SVG or radial artery (RA) grafting, in patients aged 70 years or more.

\section{PATIENTS AND METHODS}

This retrospective review of medical records and the use of a telephone questionnaire for obtaining follow-up information were approved by the institutional review board of the Tel Aviv Medical Center. Informed consent was waived. Between 1996 and 2008, 1045 patients aged 70 years or more with multivessel coronary artery disease underwent left-sided (left anterior descending artery and circumflex system) BITA grafting. They were compared with 582 patients who underwent CABG with single ITAs and SVGs and 249 patients who underwent CABG with a single ITA and RA in our institution. The study comprises all patients in this age group who underwent multivessel bypass surgery during the years of the study. Follow-up, which was $98 \%$ complete, was obtained by means of the Israeli National Registry database and a telephone questionnaire that elicited nonvalidated survival information.

\section{Surgical Techniques}

Operations were performed using standard cardiopulmonary bypass (CPB) or off-pump coronary artery bypass (OPCAB). Myocardial preservation during $\mathrm{CPB}$ involved intermittent antegrade or retrograde blood cardioplegia $\left(30^{\circ} \mathrm{C}-32^{\circ} \mathrm{C}\right)$. Coronary stabilization during $\mathrm{OPCAB}$ was facilitated using CardioThoracic Systems stabilizers (CardioThoracic Systems Inc, Cupertino, Calif) or the Octopus system (Medtronic, Minneapolis, Minn). ITAs were mobilized from the chest wall as skeletonized vessels. In most cases, BITA was used to graft the left coronary system, that is, the myocardial territory supplied by the left anterior descending and circumflex arteries. Two arrangements were implemented: a free right ITA (RITA) attached proximally end-to-side on the left ITA in a T-graft configuration (composite T-graft) and an in situ BITA with an ante-aortic crossover RITA. All RAs were attached end-to-side to the LITA as a composite T-graft. The choice of configuration was determined by previously detailed technical considerations. ${ }^{12-14}$ During the study period, the choice of BITA and not single ITA and SVG or single ITA and RA was made mainly according to the surgeon's preference. Arterial revascularization is the preferred method in our department in all age groups, including the elderly. There is no significant variation in this approach among all surgeons within our group. There was a tendency not to choose BITA in emergency and critical patients and in patients with an increased risk for sternal wound complications (eg, patients with chronic obstructive pulmonary disease [COPD] or female patients with diabetes or obesity). ${ }^{15,16}$ In addition, a composite T-graft with the RA was used only when target coronary vessel stenosis was greater than $80 \%$ to $90 \%{ }^{14,17}$ The type of conduit selected for right coronary artery (RCA) grafting was not related to the configuration of the ITAs. Our strategy was to use RITAs, right gastroepiploic arteries, and RAs as grafts to the RCA branches only in the presence of a significant stenosis (ie, $>80 \%$ ). ${ }^{17}$ When the RCA system was unsuitable for arterial grafting, such as in cases with a potential for high competitive flow in the RCA, we selected SVGs as the conduit for revascularization of the RCA. To decrease the risk of spasm of the arterial grafts, all patients were treated with a high-dose intravenous infusion of isosorbide dinitrate (Isoket [UCB, Brussels, Belgium], $4-20 \mathrm{mg} / \mathrm{h}$ ) during the first 48 postoperative hours. Calcium-channel blockers (diltiazem, $90-180 \mathrm{mg} / \mathrm{d}$, orally) were given starting from the second postoperative day and continued for at least 3 subsequent months to patients whose surgery included a right gastroepiploic artery or a RA. ${ }^{13}$

\section{Definition of Terms and Data Collection}

Patients' data were analyzed according to American College of Cardiology/American Heart Association Clinical Data Standards. ${ }^{18}$ Chronic renal failure was diagnosed if the creatinine level exceeded $1.8 \mathrm{mg} / \mathrm{dL}$. Peripheral vascular disease included all symptomatic and asymptomatic extracoronary arteriopathy. Cerebrovascular disease included a history of any cerebrovascular event with or without permanent neurologic damage. Our definition of "emergency operation" is based on the Society of Thoracic Surgeons guidelines and includes patients undergoing operation within 24 hours of cardiac catheterization; those with ongoing angina, acute evolving myocardial infarction, or pulmonary edema; or those in cardiogenic shock. ${ }^{19}$ Patients who required emergency surgery and were not stabilized after intra-aortic balloon counterpulsation usually underwent operation using 1 ITA combined with SVGs. A perioperative myocardial infarction was defined by the appearance of new $Q$ waves on the electrocardiogram associated with elevated levels of creatine phosphokinase-MB fraction greater than $50 \mathrm{mU} / \mathrm{mL}$. A cerebrovascular accident was defined as a new permanent neurologic deficit and computed tomography evidence of cerebral infarction. Deep sternal infection in this setting was defined as the presence of deep infection in combination with late dehiscence requiring sternectomy.

\section{Statistical Analysis}

Data are expressed as the mean \pm standard deviation or as a proportion. The chi-square test and 2-sample $t$ tests were used to compare discrete and continuous variables, respectively. Expected operative mortality was calculated using the logistic European System for Cardiac Operative Risk Evaluation (euroSCORE) ${ }^{20}$ and compared with the observed operative (30-day) mortality. Multivariable logistic regression analysis was used to predict early mortality and early morbidity events by various risk factors. The odds ratios (ORs) and 95\% confidence intervals (CIs) were compiled. The postoperative survival of each group was expressed by the KaplanMeier method, and survival curves were compared by the log-rank test.

The median follow-up for the BITA, RA, and SVG groups were 8.8, 9.1, and 7.4 years, respectively. Twenty-five percent of the BITA, RA, and SVG groups were followed for more than $12.5,10.8$, and 10.6 years, respectively, and $10 \%$ were followed for more than $14.8,11.7$, and 12.5 years, respectively.

The Cox proportional hazard model was used to evaluate the influence of preoperative variables and operative data on late and overall mortality. The Cox model was used to compare adjusted survival between the various conduit groups after controlling for differences between groups in 
TABLE 1. Patients' characteristics $(\mathbf{N}=1876)$

\begin{tabular}{|c|c|c|c|c|c|c|c|c|c|}
\hline \multirow[b]{2}{*}{ No. } & \multicolumn{2}{|c|}{ Total } & \multicolumn{2}{|c|}{ BITA } & \multicolumn{2}{|c|}{$\mathbf{R A}$} & \multicolumn{2}{|c|}{ SVG } & \multirow[t]{2}{*}{$P$ value } \\
\hline & & & 1045 & $55.7 \%$ & 249 & $13.3 \%$ & 582 & $31 \%$ & \\
\hline Age $<75$ y & \multicolumn{2}{|c|}{$812(43.2 \%)$} & \multicolumn{2}{|c|}{$507(48.5 \%)$} & \multicolumn{2}{|c|}{$86(34.5 \%)$} & \multicolumn{2}{|c|}{$219(37.6 \%)$} & $<.001$ \\
\hline Age $75-79 y$ & 686 & $36.6 \%$ & 368 & $35.2 \%$ & 105 & $42.2 \%$ & 213 & $36.6 \%$ & .712 \\
\hline Age $80+y$ & 378 & $20.1 \%$ & 170 & $16.3 \%$ & 58 & $23.3 \%$ & 150 & $25.8 \%$ & $<.001$ \\
\hline Female gender & 584 & $31.1 \%$ & 282 & $27 \%$ & 106 & $42.6 \%$ & 196 & $33.7 \%$ & $<.001$ \\
\hline NIDDM & 610 & $32.5 \%$ & 322 & $30.8 \%$ & 94 & $37.8 \%$ & 194 & $33.3 \%$ & .106 \\
\hline IDDM & 57 & $3 \%$ & 15 & $1.4 \%$ & 13 & $5.2 \%$ & 29 & $5 \%$ & $<.001$ \\
\hline COPD & 169 & $9 \%$ & 57 & $5.5 \%$ & 37 & $14.9 \%$ & 75 & $12.9 \%$ & $<.001$ \\
\hline Peripheral vascular disease & 394 & $21 \%$ & 224 & $21.4 \%$ & 65 & $26.1 \%$ & 105 & $18 \%$ & .029 \\
\hline Cerebrovascular disease & 299 & $15.9 \%$ & 143 & $13.7 \%$ & 54 & $21.7 \%$ & 102 & $17.5 \%$ & .004 \\
\hline $\mathrm{EF} \leq 30 \%$ & 146 & $7.8 \%$ & 86 & $8.2 \%$ & 15 & $6 \%$ & 45 & $7.7 \%$ & .109 \\
\hline $30 \%<\mathrm{EF}<50 \%$ & 153 & $8.9 \%$ & 56 & $7.5 \%$ & 66 & $9.6 \%$ & 31 & $11.2 \%$ & .137 \\
\hline Unstable angina pectoris & 1272 & $67.8 \%$ & 668 & $63.9 \%$ & 178 & $71.5 \%$ & 426 & $73.2 \%$ & $<.001$ \\
\hline Acute $\mathrm{MI} \leq 1 \mathrm{wk}$ & 365 & $19.5 \%$ & 190 & $18.2 \%$ & 39 & $15.7 \%$ & 136 & $23.4 \%$ & .011 \\
\hline Recent $\mathrm{MI} \leq 3 \mathrm{mo}$ & 399 & $21.3 \%$ & 263 & $25.2 \%$ & 30 & $12 \%$ & 106 & $18.2 \%$ & $<.001$ \\
\hline 3-vessel disease & 1445 & $75.5 \%$ & 802 & $76.4 \%$ & 196 & $78.7 \%$ & 417 & $71.6 \%$ & .271 \\
\hline Left main disease & 616 & $32.9 \%$ & 355 & $34 \%$ & 66 & $26.5 \%$ & 195 & $33.5 \%$ & $<.001$ \\
\hline Preoperative IABP & 148 & $7.9 \%$ & 67 & $6.4 \%$ & 19 & $7.6 \%$ & 62 & $10.7 \%$ & .010 \\
\hline Critical preoperative state & 101 & $5.4 \%$ & 61 & $5.8 \%$ & 6 & $2.4 \%$ & 36 & $6.1 \%$ & $<.001$ \\
\hline Emergency operation & 357 & $19 \%$ & 163 & $15.6 \%$ & 50 & $20.1 \%$ & 144 & $24.7 \%$ & $<.001$ \\
\hline Repeat operation & 52 & $2.8 \%$ & 29 & $2.5 \%$ & 6 & $2.4 \%$ & 17 & $2.9 \%$ & .919 \\
\hline $\mathrm{CRF}(\mathrm{CR}>1.8)$ & 256 & $13.7 \%$ & 118 & $11.3 \%$ & 32 & $1.7 \%$ & 106 & $18.3 \%$ & $<.001$ \\
\hline Additive euroSCORE Median (IQR) & & & \multicolumn{2}{|c|}{$7(5.6-9)$} & \multicolumn{2}{|c|}{$8(6-11)$} & \multicolumn{2}{|c|}{$8(6-11)$} & $<.001$ \\
\hline Logistic euroSCORE Median (IQR) & & & \multicolumn{2}{|c|}{$8(4.5-14.5)$} & \multicolumn{2}{|c|}{$10.5(6-23)$} & \multicolumn{2}{|c|}{$11(5-23)$} & $<.001$ \\
\hline OPCAB & 609 & $32.5 \%$ & 316 & $30.3 \%$ & 126 & $50.6 \%$ & 167 & $28.7 \%$ & $<.001$ \\
\hline Bypass grafts $\geq 3$ & 1284 & $68.4 \%$ & 736 & $70.7 \%$ & 170 & $68.2 \%$ & 381 & $65.4 \%$ & .008 \\
\hline Sequential grafts & 1023 & $59.7 \%$ & 429 & $57.4 \%$ & 415 & $60.3 \%$ & 179 & $64.4 \%$ & .113 \\
\hline
\end{tabular}

BITA, Bilateral internal thoracic artery; RA, radial artery; SVG, saphenous vein graft; NIDDM, noninsulin-dependent diabetes mellitus; IDDM, insulin-dependent diabetes mellitus; $C O P D$, chronic obstructive pulmonary disease; $E F$, ejection fraction; $M I$, myocardial infarction; $I A B P$, intra-aortic balloon pump; $C R F$, chronic renal failure; $C R$, creatnin level; euroSCORE, European System for Cardiac Operative Risk Evaluation; IQR, interquartile range; $O P C A B$, off-pump coronary artery bypass.

preoperative and operative characteristics. The results of the Cox analysis were expressed as hazard ratios (HRs) and 95\% CI.

To account for patient selection and differences between patients on the basis of all preoperative and intraoperative variables, a saturated multinomial logistic regression model was used to calculate the probability that a patient would be treated with arterial grafts or SVG. Preoperative variables used to generate the propensity score were age, gender, diabetes, hyperlipidemia, peripheral vascular disease, emergency surgery, critical preoperative state, recent myocardial infarction, acute myocardial infarction repeat operation, renal insufficiency, congestive heart failure, COPD, unstable angina, left main disease, number of diseased vessels, and left ventricular ejection fraction. The same variables were also used in the multivariable analyses, in addition to the following intraoperative variables: OPCAB, number of vessels grafted, sequential grafting RA or SVG conduits, and revascularization of the right coronary system. The propensity scores were converted into logit units and later used in multivariable logistic regressions and Cox proportional hazard models. ${ }^{21,22}$ We initially developed the models without the propensity score, which was later forced into the models for better adjustment. Several multivariable binary logistic regression models with forward conditional variable selection were developed to identify independent associations with outcome. The propensity score was forced into all models. Each model was performed once solely with preoperative variables and once with both preoperative and intraoperative variables.

To present the expected annual survival of the general population based on our sample of patients, we used the 2005 to 2009 Complete Life Tables published by the National Central Bureau of Statistics ${ }^{22,23}$ to calculate the annual survival for each patient according to age and gender, up to 15 years. Statistical analysis was performed using SPSS for Windows version 21 (SPSS Inc, Chicago, Ill).

\section{RESULTS}

Table 1 lists the study patients' preoperative characteristics according to the conduits used for bypass grafting. Prevalence of patients aged more than 75 years, female gender, insulin-treated diabetes, peripheral vascular disease, critical preoperative state, emergency operation, chronic renal failure, and COPD was higher in the SVG groups, whereas congestive heart failure and recent myocardial infarction were more prevalent in the BITA and SITA + RA groups. The logistic euroSCORE predicted mortality of the SVG group was higher. Operative mortality and occurrences of sternal infection, stroke, and perioperative myocardial infarction in the 3 groups were similar (Table 2). The 30-day mortality rates $(3.7 \%, 3.2 \%$, and $3.3 \%$ in the BITA, RA, and SVG groups, respectively) were lower than the logistic euroSCORE predicted mortality $(12.35 \%, 17.95 \%$, and $18.79 \%$, respectively, $P<.001)$. Female gender, COPD, chronic renal failure, ejection 
TABLE 2. Morbidity and mortality by surgical technique

\begin{tabular}{|c|c|c|c|c|c|c|c|c|c|}
\hline \multirow[b]{2}{*}{ Factor } & \multicolumn{2}{|c|}{ Total } & \multicolumn{2}{|c|}{ BITA } & \multicolumn{2}{|c|}{$\mathbf{R A}$} & \multicolumn{2}{|c|}{ SVG } & \multirow[b]{2}{*}{$P$ value } \\
\hline & No. & $\%$ & No. & $\%$ & No. & $\%$ & No. & $\%$ & \\
\hline 30-d mortality & 66 & 3.5 & 39 & 3.7 & 8 & 3.2 & 19 & 3.3 & .852 \\
\hline euroSCORE predicted mortality (mean $\pm \mathrm{SD}$ ) & 15.09 & \pm 16.30 & 12.35 & \pm 12.8 & 17.95 & \pm 18.07 & 18.79 & \pm 19.75 & $<.001$ \\
\hline Postoperative sternal infection & 31 & 1.7 & 18 & 1.7 & 2 & 0.8 & 11 & 1.9 & .511 \\
\hline Postoperative CVA & 61 & 3.3 & 38 & 3.6 & 3 & 1.2 & 20 & 3.2 & .144 \\
\hline Perioperative MI & \multicolumn{2}{|c|}{$32(1.7 \%)$} & \multicolumn{2}{|c|}{$13(1.2 \%)$} & \multicolumn{2}{|c|}{$7(2.8 \%)$} & \multicolumn{2}{|c|}{$12(2.1 \%)$} & .167 \\
\hline \multirow[t]{2}{*}{ 3-y actuarial survival } & & & & & & & & & $<.001$ \\
\hline & & & \multicolumn{2}{|c|}{$85.6 \% \pm 1.1 \%$} & \multicolumn{2}{|c|}{$87.4 \pm 2.1$} & \multicolumn{2}{|c|}{$82.1 \pm 1.6$} & \\
\hline \multirow[t]{2}{*}{ 5-y actuarial survival } & & & \multirow{2}{*}{\multicolumn{2}{|c|}{$78.2 \% \pm 1.3 \%$}} & \multirow{2}{*}{\multicolumn{2}{|c|}{$75.7 \pm 2.7$}} & \multirow{2}{*}{\multicolumn{2}{|c|}{$70.2 \pm 1.9$}} & $<.001$ \\
\hline & & & & & & & & & \\
\hline \multirow[t]{2}{*}{ 10-y actuarial survival } & & & \multirow{2}{*}{\multicolumn{2}{|c|}{$56.7 \pm 1.6$}} & & & & & $<.001$ \\
\hline & & & & & \multicolumn{2}{|c|}{$54.3 \pm 3.32$} & \multicolumn{2}{|c|}{$45.1 \pm 2.2$} & \\
\hline
\end{tabular}

BITA, Bilateral internal thoracic artery; $R A$, radial artery; SVG, saphenous vein graft; euroSCORE, European System for Cardiac Operative Risk Evaluation; SD, standard deviation; $C V A$, cerebrovascular accident; $M I$, myocardial infarction.

fraction $30 \%$ or less, preoperative intra-aortic balloon pump, emergency operation, and repeat operations were independent predictors of increased operative mortality (Table 3). Off-pump operations (OPCAB) were associated with reduced early mortality $(2.1 \%$ vs $4.2 \%$ in patients undergoing operation with $\mathrm{CPB}, P=.024)$. The type of conduit was not found to be a significant predictor for operative mortality. Sternal infection occurred in 31 patients (1.7\%) (Table 2). COPD (OR, 4.098; 95\% CI, 1.577$10.753 ; P=.004)$ was identified as the only independent predictor of sternal wound infection.

The mean follow-up was $8.17 \pm 4.45$ years. The 10 -year survival (Kaplan-Meier) in the SVG group was significantly lower than in the other 2 groups $(45 \%$ in the SVG group vs $56 \%$ and $54 \%$ in the BITA and RA groups, respectively, $P<.001$, log-rank test) (Table 2). It was also lower than the survival of the gender- and age-matched general population (Figure 1). Assignment to the SVG group was also associated with decreased Cox-adjusted survival (HR, 1.21; 95\% CI, 1.04-1.40; $P<.005$ compared with

TABLE 3. Independent predictors for early mortality

\begin{tabular}{llr}
\hline & & $\begin{array}{c}\boldsymbol{P} \\
\text { value }\end{array}$ \\
\hline Female gender & OR, 0.330; 95\% CI, 0.188-0.579 & $<.001$ \\
COPD & OR, 0.411; 95\% CI, 0.204-0.829 & .013 \\
CRF & OR, 0.406; 95\% CI, 0.206-0.766 & .005 \\
EF $\leq 30 \%$ & OR, 0.356; 95\% CI, 0.182-0.698 & .003 \\
IABP & OR, 0.428; 95\% CI, 0.201-0.931 & .028 \\
Emergency operation & OR, 0.380; 95\% CI, 0.194-0.746 & .005 \\
Repeat operation & OR, 0.252; 95\% CI, 0.089-0.714 & .010 \\
OPCAB & OR, 2.116; 95\% CI, 1.089-4.115 & .027 \\
Propensity & 95\% CI, 0.521-3.724 & .900 \\
Conduit (BITA, RA, or SVG) & OR, 1.282; 95\% CI, 0.521-3.724 & .157 \\
\hline$O R$, Odds ratio; $C I$, confidence interval; $C O P D$, chronic obstructive pulmonary dis- \\
ease; $C R F$, chronic renal failure; $E F$, ejection fraction; $I A B P$, intra-aortic balloon \\
pump; $O P C A B$, off-pump coronary artery bypass; $B I T A$, bilateral internal thoracic \\
artery; $R A$, radial artery; $S V G$, saphenous vein graft. &
\end{tabular}

the BITA group and HR, 1.36; 95\% CI, 1.09-1.69; $P<.011$ compared with the RA group) (Table 4).

\section{DISCUSSION}

Because of their resistance to atherosclerosis, ITA grafts have better long-term patency than SVGs, and this improved patency is believed to be responsible for the better survival, the decreased recurrence of angina, and the lesser need for reintervention when they are used to bypass the left anterior descending artery. ${ }^{1,2,24}$ Despite improved longterm outcome when using 2 ITAs, the application of BITA grafting in the elderly is controversial because of their shorter life expectancy and the increased risk of sternal dehiscence and sternal infection caused by the more extensive devascularization. ${ }^{4,5}$ Harvesting the ITA as a wide musculofascial pedicle with the aid of electrocautery was

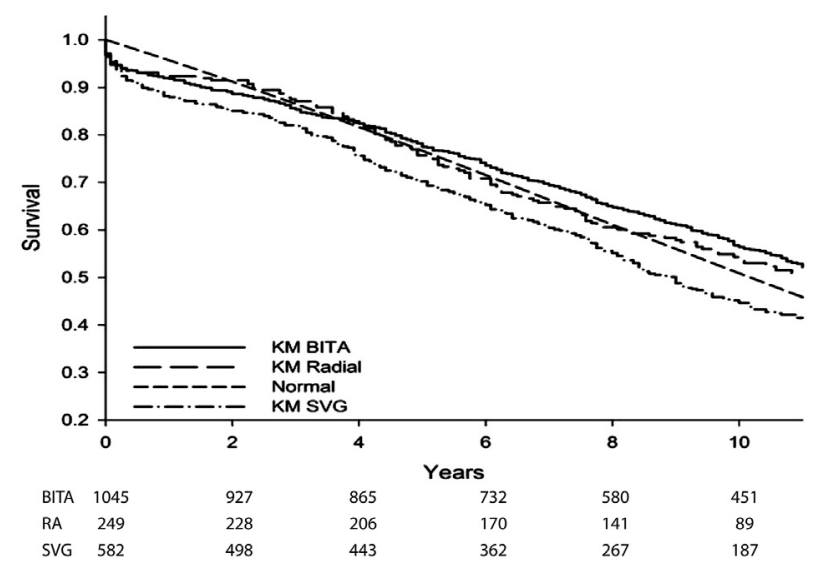

FIGURE 1. Kaplan-Meier curves comparing survival of elderly patients with gender- and age-matched individuals in the general Israeli population. KM BITA, survival curve of BITA group (10-year survival; 95\% CI, 52.859.2); KM Radial, survival curve of RA group (10-year survival; $95 \% \mathrm{CI}$, 47.4-60.6); KM SVG, survival curve of SVG group (10-year survival; 95\% CI, 40.6-49.4). KM, Kaplan-Meier; BITA, bilateral internal thoracic artery; $S V G$, saphenous vein graft; $R A$, radial artery. 
TABLE 4. Independent predictors for overall (early + late) mortality

\begin{tabular}{llr}
\hline & & $P$ value \\
\hline Age $80+\mathrm{y}$ & HR, 0.500; 95\% CI, 0.412-0.605 & $<.001$ \\
Age 75-79 y & HR, 0.733; 95\% CI, 0.617-0.807 & $<.001$ \\
DM & HR, 0.732; 95\% CI, 0.636-0.840 & $<.001$ \\
COPD & HR, 0.581; 95\% CI, 0.466-0.724 & $<.001$ \\
CHF & HR, 0.657; 95\% CI, 0.547-0.771 & $<.001$ \\
Emergency operation & HR, 0.801; 95\% CI, 0.681-0.992 & .007 \\
PVD & HR, 0.801; 95\% CI, 0.692-0.949 & .009 \\
CVD & HR, 0.803; 95\% CI, 0.673-0.959 & .015 \\
Repeat operation & HR, 0.496; 95\% CI, 0.351-0.700 & $<.001$ \\
Conduit - BITA & HR, $1.210 ; 95 \% \mathrm{CI}, 1.033-1.404$ & .005 \\
Conduit - RA & HR, $1.358 ; 95 \% \mathrm{CI}, 1.097-1.692$ & .011 \\
Propensity & $95 \% \mathrm{CI}, 1.097-1.692$ & .410 \\
\hline
\end{tabular}

$H R$, Hazard ratio; $C I$, confidence interval; $D M$, diabetes mellitus; $C O P D$, chronic obstructive pulmonary disease; $C H F$, congestive heart failure; $P V D$, peripheral vascular disease; $C V D$, cerebrovascular disease; BITA, bilateral internal thoracic artery; $R A$, radial artery.

shown to devascularize sternal collateral blood supply and expose the sternum to increased risk of poor healing, dehiscence, and infection. ${ }^{8}$ The problem of poor healing due to insufficient collateral blood supply may be more important in the elderly patient undergoing BITA grafting. Moreover, the sternum of elderly patients is sometimes more fragile because of osteoporosis and suboptimal blood supply.

In the current cohort, old age was not a contraindication for BITA grafting. Complete arterial grafting with BITAs was our preferred method of myocardial revascularization for all age groups throughout the study period when BITA grafting was performed in 1045 patients $(55.7 \%)$ aged 70 years or more who were referred for CABG. An additional 249 patients $(13.3 \%)$ underwent left-sided arterial grafting (left anterior descending + circumflex arteries) using the composite T-graft technique with a free RA connected end-to-side to the left ITA. Only 582 patients $(31 \%)$ underwent CABG with a single ITA and SVG.

Operative mortality and occurrence of sternal wound complications in our study were not affected by the type of conduits that had been used (ie, BITA vs single ITA + RA or single ITA + SVGs). Moreover, the 30-day mortality rate was similar in the 3 groups $(3.7 \%, 3.2 \%$, and $3.3 \%$ for the BITA, RA, and SVG conduits, respectively) and lower than the logistic euroSCORE-predicted mortality $(12.35 \%, 17.95 \%$, and $18.79 \%$, respectively, $P<.001)$. Multivariate logistic regression analysis did not find the type of conduit as being a significant predictor for operative mortality. Sternal infection occurred in 31 patients $(1.7 \%)$, and it was not significantly different between groups $(1.7 \%, 0.8 \%$, and $1.9 \%$ in the BITA, RA, and SVG groups, respectively). These findings may be related to the use of the skeletonization technique when harvesting ITAs for BITA grafting. ${ }^{7,13,14,16}$ This harvesting technique preserves collateral blood flow to the sternum, thus decreasing sternal bone devascularization and the associated risk of sternal infection.

COPD was identified as the only independent predictor of sternal wound infection in this cohort of elderly patients. Neither increased age nor the type of conduit was found to be significant risk factor for sternal infection (logistic regression analysis). The occurrence of sternal infection in the BITA subset in our study is similar to that published recently in the Arterial Revascularisation Trial, a prospective randomized multicenter study in which ITAs were harvested as skeletonized vessels. ${ }^{25}$ The increased rate of sternal infection in the subset of SVG in our study compared with that in the Arterial Revascularisation Trial is probably related to differences in preoperative patient characteristics between the 2 studies.

The main finding of our study is the better long-term survival of elderly patients undergoing arterial myocardial revascularization compared with the survival of those undergoing revascularization with single ITAs and SVGs. Ten-year survival (Kaplan-Meier) of the SVG group was significantly lower $(45 \%$ in the SVG group vs $56 \%$ and $54 \%$ in the BITA and RA groups, respectively). It was also lower than the $51 \% 10$-year survival of the genderand age-matched general population. Assignment to the SVG group was also associated with decreased Coxadjusted survival (Table 4). The only large series (1467 patients) that compared BITA with single ITA and SVG grafting in elderly patients was reported by Galbut and colleagues ${ }^{26}$ and Kurlansky and colleagues. ${ }^{27}$ The outcomes of that cohort are similar to our current results. Patients with BITAs had a lower hospital mortality $(3.1 \%)$ than patients with a single ITA and SVG $(6.4 \%)$, and the late survival (mean, 43 months) also was better $(69.7 \%$ vs $60.7 \%$, respectively). ${ }^{26}$

\section{Study Limitations}

The limitations of our study include its retrospective nature. Postoperative angiograms and coronary computed tomography angiograms were available for only a small number of patients, mostly the symptomatic ones, and therefore could not be included in this report.

\section{CONCLUSIONS}

The findings of this large cohort study support the use of BITA and RA in patients aged more than 70 years of age. They show improved long-term (Kaplan-Meier) and propensity Cox-adjusted survival of elderly patients who underwent CABG with arterial grafts compared with a single ITA and SVGs. The long-term survival benefit of arterial grafting outweighs the risk of an early adverse effect of sternal wound complications. The occurrence of such complications can be reduced by the use of a single ITA and an RA and the selective use of skeletonized BITA grafting. 


\section{Conflict of Interest Statement}

Authors have nothing to disclose with regard to commercial support.

\section{References}

1. Barner HB, Swartz MI, Mudd JG, Tyras DH. Late patency of the internal mammary artery bypass conduit. Ann Thorac Surg. 1982;34:408-12.

2. BARI Investigators. The final 10 year follow up results from the BARI randomized trial. J Am Coll Cardiol. 2007;49:1600-6.

3. Taggart DP, D'Amico R, Altman DG. Effect of arterial revascularization on survival: a systematic review of studies comparing bilateral and single internal mammary arteries. Lancet. 2001;358:870-5.

4. Lytle BW, Cosgrove DM, Loop FD, Borsh J, Goormastic M, Taylor PC. Perioperative risk of bilateral internal mammary artery grafting: analysis of 500 cases from 1971-1984. Circulation. 1986;74:III37-41.

5. Kouchoukaos NT, Wareing TH, Murphy SF, Pelate C, Marshall WG Jr. Risks of bilateral internal mammary artery bypass grafting. Ann Thorac Surg. 1990;49: 210-9.

6. Borger MA, Rao V, Weisel RD, Ivanov J, Cohen G, Scully HE, et al. Deep sternal wound infection risk factors and outcomes. Ann Thorac Surg. 1998;65:1050-6.

7. Arnold M. The surgical anatomy of sternal blood supply. J Thorac Cardiovasc Surg. 1972;64:596-610.

8. Parish MA, Asai T, Grossi EA, Esposito R, Galloway AC, Colvin SB, et al. The effects of different techniques of internal mammary artery harvesting on sternal blood flow. J Thorac Cardiovasc Surg. 1992;104:1303-7.

9. Lytle BW, Blackstone EH, Loop FD, Houghtaling PL, Arnold JH, Akhrass R, et al. Two internal thoracic artery grafts are better than one. J Thorac Cardiovasc Surg. 1999;117:855-72.

10. He GW, Acuff TE, Ryan WH, Mack MJ. Risk factors for operative mortality in elderly patients undergoing internal mammary artery grafting. Ann Thorac Surg. 1994;57:1453-60.

11. Buxton BF, Komeda M, Fuller JA, Gordon I. Bilateral internal thoracic artery grafting may improve outcome of coronary artery surgery. Risk-adjusted survival. Circulation. 1998;98(19 Suppl):II1-6.

12. Pevni D, Uretzky G, Mohr A, Braunstein R, Kramer A, Paz Y, et al. Routine use of bilateral skeletonized internal thoracic artery grafting: long-term results. Circulation. 2008;118:705-12.

13. Gurevitch J, Kramer A, Locker C, Shapira I, Paz Y, Matsa M, et al. Technical aspects of double-skeletonized internal mammary artery grafting. Ann Thorac Surg. 2000;69:841-6.

14. Pevni D, Mohr R, Lev-Ran O, Paz Y, Kramer A, Frolkis I, et al. Technical aspects of composite arterial grafting with double skeletonized internal thoracic arteries. Chest. 2003;123:1348-54.
15. Medalion B, Mohr R, Frid O, Uretzky G, Nesher N, Paz Y, et al. Should bilateral internal thoracic artery grafting be used in elderly patients undergoing coronary artery bypass grafting? Circulation. 2013;127:2186-93.

16. Matsa M, Paz Y, Gurevitch J, Shapira I, Kramer A, Pevny D, et al. Bilateral skeletonized internal thoracic artery grafts in patients with diabetes mellitus. $J$ Thorac Cardiovasc Surg. 2001;121:668-74.

17. Sabik JF III, Blackstone EH. Coronary artery bypass graft patency and competitive flow. J Am Coll Cardiol. 2008;51:126-8.

18. Radford MJ, Arnold JM, Bennett SJ, Cinquegrani MP, Cleland JG, Havranek EP, et al; American College of Cardiology; American Heart Association Task Force on Clinical Data Standards; American College of Chest Physicians; International Society for Heart and Lung Transplantation; Heart Failure Society of America. ACC/AHA key data elements and definitions for measuring the clinical management and outcomes of patients with chronic heart failure: a report of the American College of Cardiology/American Heart Association Task Force on Clinical Data Standards (Writing Committee to Develop Heart Failure Clinical Data Standards): developed in collaboration with the American College of Chest Physicians and the International Society for Heart and Lung transplantation: endorsed by the Heart Failure Society of America. Circulation. 2005;112: 1888-916.

19. Clark RE. The STS Cardiac Surgery National Database: an update. Ann Thorac Surg. 1995;59:1376-80.

20. Blackstone E. Comparing apples and oranges. J Thorac Cardiovasc Surg. 2002; 123:8-15.

21. Rubin DB. Estimating causal effects from large data sets using propensity scores. Ann Intern Med. 1997;127:757-63.

22. Roques F, Michel P, Goldstone AR, Nashef SA. The logistic EuroSCORE. Eur Heart J. 2003;24:882-3.

23. Israel Central Bureau of Statistics. Population and Demography: Health. Complete Life Tables of Israel, 2005-2009. Publication No. 1450. Jerusalem, Israel: Israel Central Bureau of Statistics; 2011.

24. Loop FD, Lytle BW, Cosgrove DM. Influence of internal-mammary-artery graft on 10-year survival and other cardiac events. N Engl J Med. 1986;314:1-6.

25. Taggart DP, Altman DG, Gray AM, Lees B, Nugara F, Yu LM, et al; ART Investigators. Randomized trial to compare bilateral vs. single internal mammary coronary artery bypass grafting: 1-year results of the Arterial Revascularisation Trial (ART). Eur Heart J. 2010;20:2470-81.

26. Galbut DL, Traad EA, Dorman MJ, DeWitt PL, Larsen PB, Kurlansky PA, et al. Coronary bypass grafting in the elderly: single versus bilateral internal mammary artery grafting. J Thorac Cardiovasc Surg. 1993;106:128-35.

27. Kurlansky PA, Traad EA, Dorman MJ, Galbut DL, Zucker M, Ebra G. Thirtyyear follow-up defines survival benefit for second internal mammary artery in propensity-matched groups. Ann Thorac Surg. 2010;90:101-8.

Key Words: revascularization, BITA, CABG, octogenarians 